FERNANDO A N TOONIO NOVAIS

MARIA ARMINDA D O NASCIMENTOARRUDA

FERNANDO

ANTÔNIO NOVAIS

é professor de História do Instituto de

Economia da Unicamp e professor aposentado do Departamento de História da FFLCH-USP. É autor, entre outros, de Portugal e Brasil na Crise do Antigo Sistema Colonial (1777-1808) (Hucitec).

\title{
MARIA ARMINDA
}

DO NASCIMENTO

\section{ARRUDA é}

professora do

Departamento de Sociologia da FFLCH-

USP e autora, entre

outros, de Mitologia da

Mineiridade. O Imaginário Mineiro na Vida Política e Cultural do Brasil

(Brasiliense).

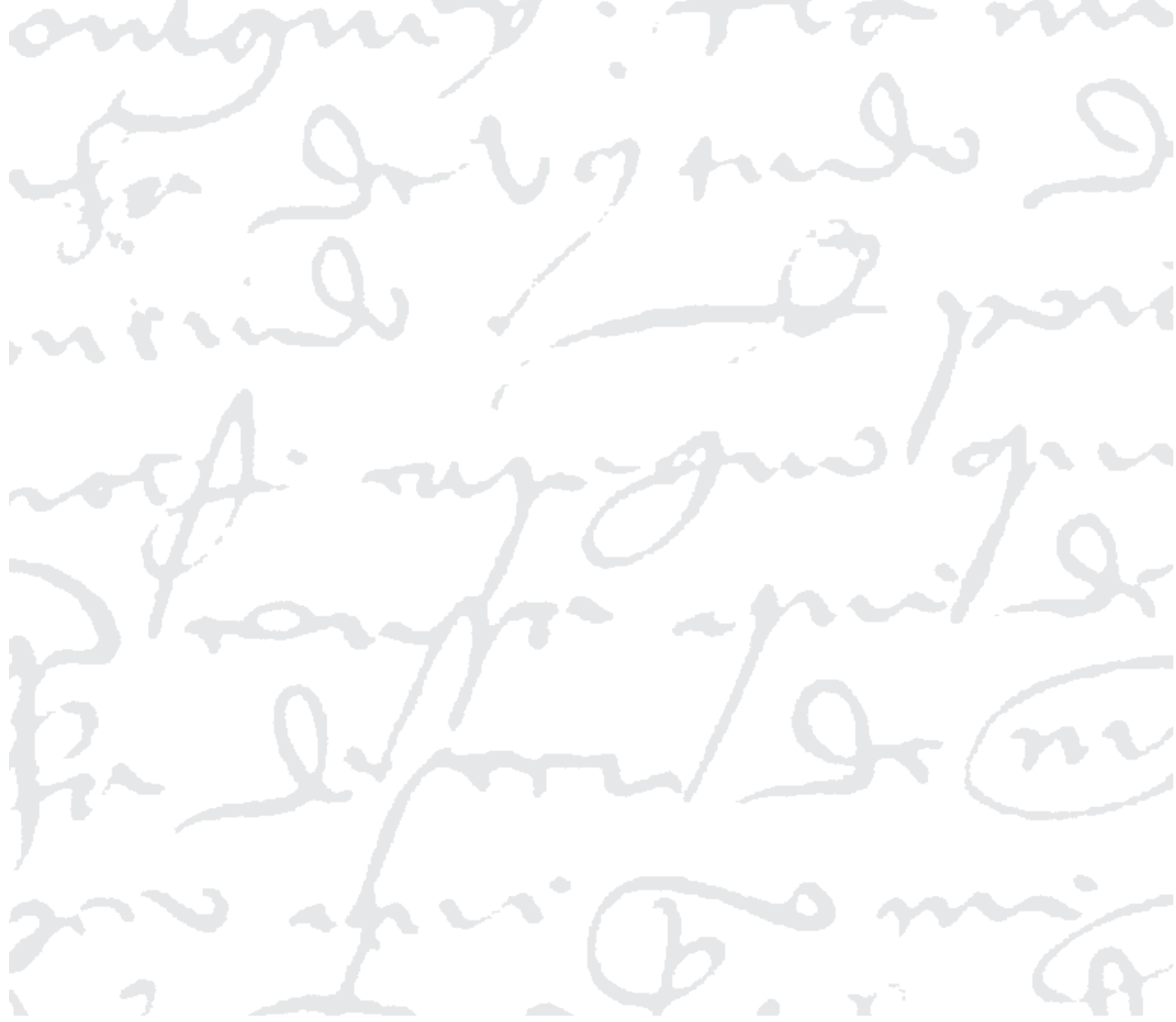


Apresentap̧ão:

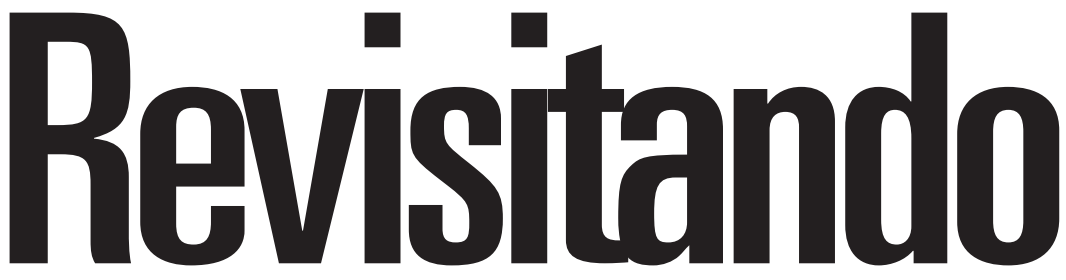

Intépretes do

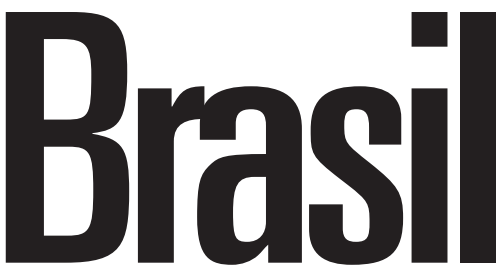




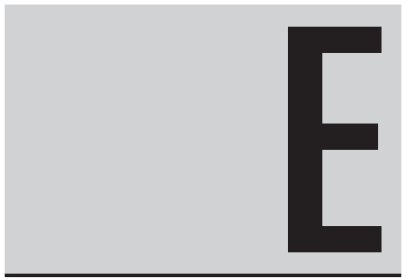

m um ensaio clássico (1), Antonio Candido grifou, indelevelmente, o significado de Sérgio Buarque de Holanda, Gilberto Freyre e Caio Prado

Jr. como marcos definidores da geração de 1930, revelada nessa aventura obstinada de reinterpretação do Brasil. Ao mesmo tempo em que recupera o significado dos anos 30, inquestionável ponto de inflexão - quando tendências recentes na historiografia enfatizavam a continuidade - , delimita as vertentes inovadoras que diferenciam cada um dos autores e circunscreve as orientações comuns, evidentes na perspectiva histórica como centro de análise. Bastaria essa observação para justificar o presente dossiê da Revista USP, nucleado em estudos sobre os três intérpretes acima referidos.

Efetivamente, nos dias que correm e pelo menos desde o texto de Antonio Candido, cientistas sociais têm se debruçado sobre a obra desses mestres, exibindo-a em múltiplos ângulos, em variadas perspectivas, a exemplo do instigante estudo de Ricardo Benzaquem Araújo (2) sobre Gilberto Freyre. Alguns desses intelectuais comparecem no presente númedo Brasil, 1969.

2 Guerra e Paz. Casa-Grande e Senzala e a Obra de Gilberto Freyre nos Anos 30, Rio de Janeiro, 1994.

3 Otilia B. F. Arantes e Paulo E. Arantes, Sentido da Formação, Rio de Janeiro, 1997.

4 Maria Arminda do Nascimento Arruda, "Florestan Fernandes e a Escola Paulista", in Sérgio Miceli (org.), Históric das Ciências Sociais no Brasil, vol. II, São Paulo, 1995.

5 Ensayos de Sociologia de La Cultura, trad. esp., Madrid, 1963. autores assinalam a obssessiva preocupação dos intelectuais no Brasil com as dimensões formativas nas diversas esferas da nossa existência como povo, como nação, como Estado (3).

Mesmo um sociólogo do porte de Florestan Fernandes, perfil acabado de intelectual acadêmico, persegue, nas suas análises, as idéias de fundamento e de formação histórica no entendimento das nossas particularidades e dos impasses do processo de mudança social. Apesar de seu estilo de reflexão afastar-se da forma ensaística, característica dos intérpretes de 30, a noção de gênese da sociedade desdobra-se na referência ao caráter próprio da nossa identidade. Segundo os seus termos, a construção de uma "moderna sociedade nos trópicos" pressupõe a superação do persistente legado do passado (4).

Efetivamente, se olharmos o conjunto da nossa trajetória, principalmente nos momentos decisivos, manifesta-se o "eterno retorno" à mesma temática, a recorrência às questões identitárias. Os intelectuais brasileiros dirigem-se, não por acaso, à busca incessante das nossas raízes, rastreando os contornos da nossa vida social. Como disse Mannheim, “é, geralmente, sabido que, apesar do livre fluir das idéias sobre as fronteiras políticas, determinados temas reaparecem só no pensamento organizado de cada país" (5).

Problemática dessa natureza conferiu o ritmo do pensamento das diferentes gerações. Assim, no período que se estende da Independência à Regência, os textos do 


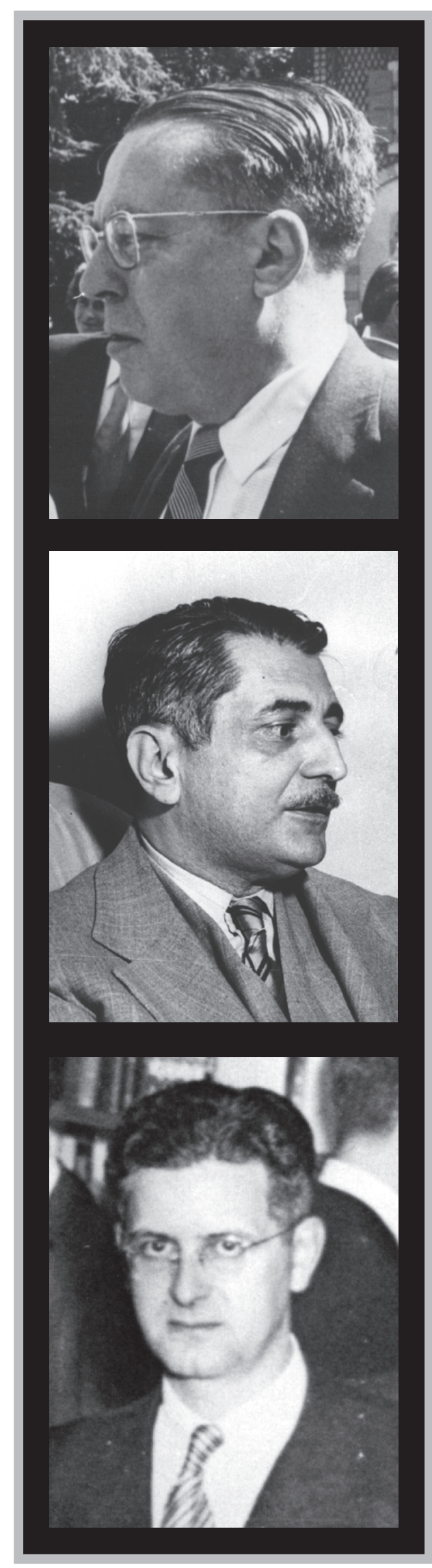

Patriarca José Bonifácio são exemplares dessa inquietação. Durante a Belle Epoque, são expressivas as figuras de Lima Barreto, Manuel Bonfim e, sobretudo, Euclides da Cunha, cujas palavras lapidares sobre a constituição do Brasil ainda ressoam: “uma nacionalidade feita por uma teoria política" (6). Com o modernismo emerge a criação genial de Mário de Andrade na personagem Macunaíma - “O herói sem nenhum caráter". Nos anos 30, estréiam os chamados intérpretes, tão bem distinguidos por Antonio Candido. Segue-se a produção acadêmica urdida na ambiência universitária.

O "sentido de formação" enlaça os vários momentos. Essa tendência comum de imersão no passado, o perquerir as raízes, a eleição da história como caminho iluminador da compreensão. Nesse diapasão, são exatamente os autores contemplados nesta publicação que se estabelecem como referências da viragem, pois formulam, definem e enquadram os procedimentos essenciais ao tratamento da identidade.

A publicação, no entanto, não se constitui em mise-au-point, como se poderá depreender da leitura das páginas que se seguem. Pretendemos explicitar tendências através das quais se arquitetam compreensões atuais, encerradas em textos de estilos diferenciados e de índoles diversas. O que os unifica, sem sombra de dúvida, é esse referencial inescapável do pensamento social no Brasil. Com este número, portanto, a Revista USP revisita uma questão clássica da nossa cultura.
De cima para

baixo, Sérgio

Buarque de

Holanda,

Gilberto Freyre

e Caio Prado Jr. 